\title{
Tooth wear: the view of the anthropologist
}

John A. Kaidonis

Published online: 29 January 2008

(C) Springer-Verlag 2007

Erratum to: Clin Oral Invest (2007)

DOI 10.1007/s00784-007-0154-8

The conflict of interest statement was missing from the original publication.

The author declares that he has no conflict of interest.

The online version of the original article can be found at http://dx.doi. org/10.1007/s00784-007-0154-8.

J. A. Kaidonis $(\square)$

School of Dentistry, University of Adelaide,

Adelaide 5005, Australia

e-mail: john.kaidonis@adelaide.edu.au 